\title{
ANALISIS KARAKTERISTIK KADAR RESIDU KARBON DAN KANDUNGAN SULFUR PRODUK MINYAK BIOSOLAR DENGAN KONSEP SIX SIGMA
}

\author{
A. Pattiruhu \\ Program Studi Teknik Industri, Fakultas Teknik Universitas Pattimura, Ambon \\ e-mail : arthurpattiruhu01@gmail.com \\ J. M. Tupan \\ Program Studi Teknik Industri, Fakultas Teknik Universitas Pattimura, Ambon \\ e-mail : johantupan@yahoo.co.id \\ A. Tutuhatunewa \\ Program Studi Teknik Industri, Fakultas Teknik Universitas Pattimura, Ambon \\ e-mail : alfredo.tutuhatunewa@gmail.com
}

\begin{abstract}
ABSTRAK
Permasalahan yang dihadapi oleh PT Pertamina (Persero) Terminal BBM Wayame adalah biosolar yang diproduksi tidak memenuhi standar kualitas yang ditetapkan. Penelitian ini bertujuan untuk memperoleh level kualitas karakteristik kadar residu karbon dan kandungan sulfur produk biosolar. Pengumpulan data dilakukan dengan pengambilan sampel biosolar. Nilai level kualitas dilakukan dengan six sigma untuk mengetahui level kualitas biosolar yang dimulai dengan tahapan identifikasi critical to quality, measure, analyze dan improvement. Hasil penelitian ini memperoleh level kualitas dari karakteristik spesifikasi biosolar untuk kadar residu carbon yaitu 3,57\% m/m dan kandungan sulfur yaitu 3,263. Perolehan level kualitas ini mennujukkan bahwa kualitas karakteristik spesifikasi biosolar belum memenuhi tujuan utama perusahaan yaitu memiliki level kualitas kelas dunia, namun perolehan ini menujukkan kualitas spesifikasi biosolar berada di atas rata-rata kualitas industri di Indonesia.
\end{abstract}

Kata Kunci : kualitas, biosolar, kadar residu karbon, kandungan sulfur, six sigma

\begin{abstract}
The problem faced by PT Pertamina (Persero) Wayame BBM Terminal is that the biodiesel produced does not meet the quality standards set. This study aims to obtain a characteristic quality level of carbon residue content and sulfur content of biodiesel products. Data collection was carried out by taking biodiesel samples. The quality level value is carried out using six sigma to determine the level of biodiversity quality, starting with the identification stages of critical to quality, measure, analyze and improvement. The results of this study obtained the quality level of the characteristics of the biodiesel specification for carbon residue content, namely $3.57 \% \mathrm{~m} / \mathrm{m}$ and sulfur content of 3.263. The acquisition of this quality level shows that the quality characteristics of the biodiesel specification have not met the main goal of the company, which is to have a world-class quality level, but this acquisition shows that the quality of biodiesel specifications is above the average industrial quality in Indonesia.
\end{abstract}

Keywords: quality, biodiesel, carbon residue content, sulfur content, six sigma

\section{PENDAHULUAN}

Persaingan kualitas produk pada era Industri 4.0 menyebabkan kompetisi antar pelaku usaha semakin kompetitif. Selain produk yang dihasilkan, suatu perusahaan juga tidak lepas dari konsumen sebagai pengguna produk. Konsumen sebagai pengguna produk tentunya berharap bahwa produk yang dibelinya akan dapat memenuhi kebutuhan dan keinginannya sehingga harapan konsumen adalah produk yang dihasilkan memiliki kualitas yang baik dan terjamin.

PT Pertamina (Persero) Terminal BBM Wayame mempunyai kewajiban serta bertanggung jawab dalam menjamin kualitas produk yang dipasarkan kepada konsumen. Persyaratan sesuai dengan spesifikasi yang berlaku harus menjadi acuan, agar dapat memenuhi tuntutan dan kebutuhan konsumen. Permasalahan yang dihadapi oleh perusahaan adalah hasil produksi biosolar yang tidak memenuhi standar yang telah ditetapkan sehingga berakibatkan kualitas biosolar yang rendah. 
Fokus penelitian ini adalah kadar residu karbon dan kandungan sulfur dari biosolar yang dihasilkan. Kadar residu karbon menunjukkan kadar fraksi hidrokarbon yang mempunyai titik didih lebih tinggi dari range bahan bakar. Adanya fraksi hidrokarbon ini menyebabkan menumpuknya residu karbon dalam ruang pembakaran yang dapat mengurangi kinerja mesin. Sementara itu, Sulfur pada bahan bakar solar akan menambah deposit pada silinder dan torak yang cepat merusak silinder dan pegas torak. Jika bahan bakar minyak mempunyai kandungan sulfur yang besar maka akan menyebabkan terjadinya keausan pada bagian mesin yang dikarenakan keberadaan oksida belerang yang terkandung di dalamnya (Rosyadi, 2016).

Perbaikan kualitas dilakukan dengan menerapkan pengendalian kualitas yang ketat. Pengendalian kualitas sangat berpengaruh terhadap kualitas biosolar yang diproduksi. Salah satu upaya untuk mengetahui level kualitas atau nilai kualitas dari suatu produk adalah dengan menggunakan Six Sigma. Pada dasarnya, Six Sigma bertujuan untuk menjangkau dan mendukung keberhasilan suatu bisnis dengan meminimasi jumlah kecacatan produk hingga menganilisis level sigma yang merupakan level kualitas dari suatu produk yang dapat memperkuat nilai produk tersebut.

\section{LANDASAN TEORI \\ Konsep Kualitas}

Dalam dunia bisnis kualitas merupakan alat yang digunakan untuk mengukur kinerja perusahaan dan mempertahankan bisnis perusahaan tersebut. Kualitas memiliki banyak definisi menurut para ahli, di antaranya:

1. Kualitas merupakan faktor-faktor yang terdapat dalam suatu barang atau hasil yang menyebabkan barang atau hasil tersebut sesuai dengan tujuan untuk apa barang atau hasil itu dimaksudkan atau dibutuhkan (Assauri, 2011).

2. Kualitas adalah keseluruhan gabungan karakteristik produk dan jasa dari pemasaran, rekayasa, pembuatan, dan pemeliharaan yang membuat produk dan jasa dimaksudkan memenuhi harapan-harapan pelanggan (Feigenbaum, 2019).

3. Kualitas merupakan kecocokan untuk pemakaian. Definisi ini menekankan orientasi pada pemenuhan harapan pelanggan (Juran, 1999).

Dengan demikian, kualitas dapat digunakan untuk strategi perusahaan agar dapat memenangkan persaingan bisnis yang ketat. Kualitas juga merupakan tingkat baik buruknya atau taraf atau derajat sesuatu. Kata kualitas memiliki banyak arti berbeda dan bervariasi, dari yang konvensional sampai ke yang lebih strategik. Definisi konvensional dari kualitas biasanya menggambarkan karakteristik langsung dari suatu produk seperti performansi, keandalan, mudah dalam penggunaan, estetika dan sebagainya. Sementara itu, definisi strategik dari kualitas menyatakan bahwa kualitas adalah segala sesuatu yang mampu memenuhi keinginan atau kebutuhan pelanggan (meeting the need of customers).

\section{Pengendalian Kualitas}

Pengendalian kualitas adalah suatu aktivitas yang berorientasi pada tindakan pencegahan kerusakan dan bukan berfokus pada usaha untuk memperbaiki kerusakan saja (Gaspersz, 1998), sedangkan menurut (Assauri, 2011) bahwa pengendalian kualitas adalah suatu usaha untuk mempertahankan mutu atau kualitas dari barang yang dihasilkan agar sesuai dengan spesifikasi produk yang telah ditetapkan berdasarkan kebijakan pimpinan perusahaan. Dengan demikian, dapat disimpulkan bahwa pengendalian kualitas adalah suatu aktivitas yang dilakukan untuk mencegah dan meminimalisir kerusakan barang dari suatu produk yang tidak sesuai dengan spesifikasi.

Beberapa tujuan dari dilakukannya pengendalian kualitas diantaranya (Assauri, 2011):

1. Agar barang yang dihasilkan bisa mencapai target kualitas yang telah ditetapkan oleh perusahaan.

2. Mengusahakan agar biaya pemeriksaan dapat menjadi seminimal mungkin.

3. Mengusahakan agar biaya desain produk dan proses dengan menggunakan kualitas produksi tertentu dapat menjadi seminimal mungkin.

4. Mengusahakan agar biaya produksi dapat menjadi seminimal mungkin.

Berdasarkan tujuan pengendalian kualitas diatas, maka dapat disimpulkan bahwa tujuan pengendalian kualitas adalah untuk mendapatkan jaminan bahwa kualitas produk maupun jasa dihasilkan akan sesuai dengan standar kualitas yang telah ditetapkan dengan mengoptimalkan pengeluaran agar seminimal mungkin.

\section{Konsep Six Sigma}

Metode six sigma dikembangkan oleh perusahaan Amerika Serikat pada tahun 1980-an. Six sigma diperkenalkan oleh Mikel Harry dan Richard Shroeder. Six sigma merupakan metode statistik yang sistematik untuk mengurangi variasi dalam setiap proses dari bisnis kunci yang berhubungan langsung dengan pelanggan. Berikut ini adalah beberapa definisi dari six sigma: 
1. Six Sigma adalah penyelesaian persoalan yang disebut dengan DMAIC, dimana DMAIC adalah sekumpulan alat yang digunakan untuk mengidentifikasi, menganalisis dan mengeleminasi sumber variasi dalam sebuah proses (Bentley dan Davis, 2009).

2. Six sigma adalah strategi bisnis yang didalamnya disediakan peralatan untuk memperbaiki kemampuan dari bisnis prosesnya (Yang dan El-haik, 2003).

Six sigma adalah suatu visi peningkatan kualitas menuju target 3.4 kegagalan per sejuta kesempatan untuk setiap transaksi produk serta upaya giat menuju kesempurnaan atau zero defect (Gasperz, 2002 dalam Fauziah, Harsono, dan Liansari, 2014).

Dalam penerapan six sigma ada lima langkah yang disebut DMAIC. Berikut ini adalah langkah-langkah dalam menyelesaikan permasalahan dengan menggunakan metode DMAIC:

1. Tahapan Define

Tahapan ini merupakan tahapan awal dalam menyelesaikan masalah dengan menggunakan metode Six Sigma. Pada tahapan ini, akan didefinisikan permasalahan dan mengidentifikasi Critical to Quality (CTQ) dan jenis kecacatan dari produk.

2. Tahapan Measure

Tahapan ini merupakan lanjutan dari tahapan define. Pada tahapan ini akan dilakukan pengukuran terhadap data hasil pengukuran. Pengukuran yang dimaksud adalah:

a. Defect Per Opportunity

Defect Per Opportunity atau DPO, merupakan ukuran kegagalan yang dihitung dalam program peningkatan kualitas Six Sigma, yang menunjukkan banyaknya cacat atau kegagalan per kesempatan, dapat dihitung dengan rumus:

$$
D P O=\frac{\text { Banyaknya cacat yang ditemukan }}{\text { banyaknya unit yang diperiksa } X \text { jumlah CTQ }}
$$

b. Defect Per Million Opportunity

Defect Per Miliion Opportunity atau DPMO adalah langkah lanjutan dari perhitungan DPO. Defect Per Million Opportunity (DPMO) merupakan ukuran kegagalan dalam program peningkatan six sigma yang menunjukkan kegagalan per satu juta kesempatan. Target dari pengendalian kualitas six sigma sebesar 3.4 DPMO seharusnya tidak diinterpretasikan sebagai 3.4 unit produk tunggal terdapat rata-rata kesempatan gagal dari suatu karakteristik CTQ hanya 3.4 kegagalan per satu juta kesempatan.

$$
D P M O=\frac{\text { Jumlah } C T Q}{\text { Jumlah cacat } X \text { Hasil produksi }} x 1.000 .000
$$

c. Level Sigma

Setelah mendapatkan nilai DPMO maka langkah selanjutnya adalah menghitung nilai sigma atau level sigma. Penentuan level sigma adalah dengan cara mengkonversi nilai DPMO pada tabel sigma. Jika level sigma yang didapatkan tidak ada dalam tabel sigma, maka dilakukan interpolasi level sigma dengan menggunakan persamaan interpolasi yaitu:

$$
X=N S B+\left\{\left(\frac{D P M O-N S B}{D P M O N S B-N S A}\right)(N S A-N S B)\right\}
$$

Tingkatan Pencapaian Kualitas Berdasarkan Sigma

\begin{tabular}{|c|l|}
\hline Tingkat Pencapaian Sigma & \multicolumn{1}{|c|}{ Deffect Per Million Opportunity } \\
\hline 1-Sigma & 691.462 (sangat tidak kompetitif) \\
\hline 2-Sigma & 308.538 \\
\hline 3-Sigma & 66.807 (Rata-rata industri Indonesia) \\
\hline 4-Sigma & 6.210 (Rata-rata industri USA) \\
\hline 5-Sigma & 233 (Rata-rata industri Jepang) \\
\hline 6-Sigma & 3.4 (Industri kelas dunia) \\
\hline
\end{tabular}

Sumber: (George, 2003)

3. Tahapan Analyze

Tujuan dari tahapan ini adalah menganalisa setiap pengolahan data yang telah dibahas pada tahapan measure. Pada tahapan ini juga akan dianalisis tentang faktor-faktor yang mempengaruhi kualitas. Dan akan digambarkan dalam bentuk fishbone diagram. Fishbone diagram atau yang biasa disebut dengan cause and effect diagram merupakan salah satu alat bantu pada seven tools yang dipergunakan untuk mengidentifikasi dan menunjukkan hubungan antara sebab dan akibat agar dapat menemukan akar penyebab dari suatu permasalahan. 
4. Tahapan Improve

Peningkatan kualitas dari suatu produk sangat penitng. Pada tahapan ini akan dianalisa setiap faktorfaktor yang mempengaruhi kualitas suatu produk yang telah dibahas pada tahapan analyze dan akan dijadikan sebagai ide-ide baru berupa solusi untuk perbaikan dan peningkatan kualiats produk.

5. Tahapan Control

Control merupakan tahap operasional terakhir dalam peningkatan kualitas menggunakan metode six sigma. Pada tahapan ini, semua tahapan yang telah dibahas sebelumnya akan dijadikan sebagai pedoman yang baru untuk menetapkan standar kualitas agar kualitas dari suatu produk menjadi lebih baik.

\section{Biosolar}

Biosolar atau B20 adalah salah satu bahan bakar diesel campuran petroleum diesel atau solar $80 \%$ dengan Fatty Acid Methyl Ester (FAME) 20\%. Biosolar ini dirancang sebagai bahan bakar minyak terbarukan sesuai dengan Surat Keputusan Menteri Energi Dan Sumber Daya Mineral nomor 1936 K/10/MEM/2018 tentang pengadaan bahan bakar nabati jenis biodiesel untuk pencampuran jenis bahan bakar minyak umum. Karena B20 adalah bahan bakar diesel dengan kandungan dua jenis bahan bakar didalamnya yaitu solar atau B0 dan FAME atau B100 maka kandungan yang tercipta dari B20 adalah kandungan murni yang mengandung dua unsur dua jenis bahan bakar diatas dengan memenuhi spesifikasi parameter yang telah ditetapkan, sehingga pendistribusian B20 memiliki mutu atau kualitas yang baik.

\section{METODOLOGI PENELITIAN}

Penelitian ini dilakukan melalui alur yang direncanakan sebagai berikut.

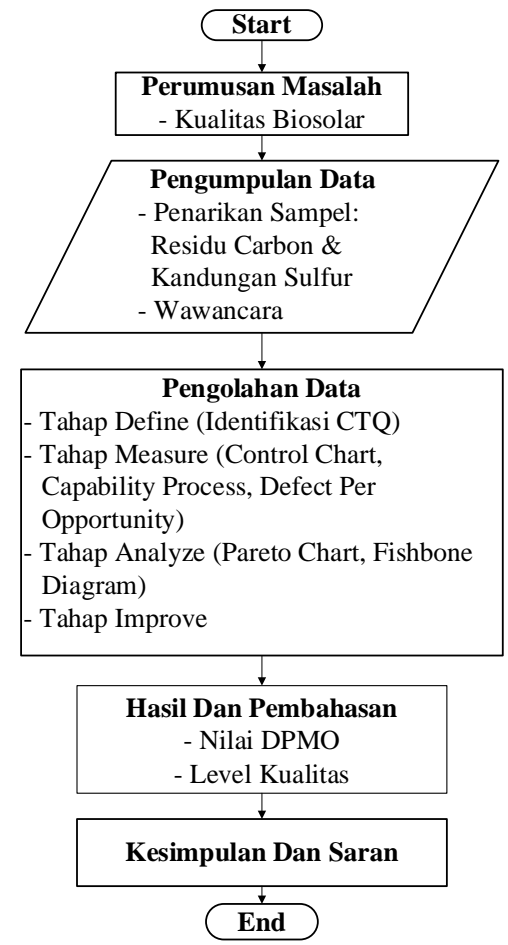

Flowchart penelitian

Pada penelitian ini, salah satu metode yang digunakan dalam upaya mendapatkan data yaitu dengan penarikan sampel. Sampel biosolar yang dilakukan pengujian adalah $100 \mathrm{~mL}$ tabung reaksi. Setelah proses pembuatan biosolar telah selesai, penulis bersama dengan Petugas Pengambil Contoh (PPC) membawa sampel ke laboratorium untuk dilakukan pengujian kualitas. Dari hasil penelitian yang dilakukan didapatkan variabel-variabel yang berpengaruh dalam kualitas bahan bakar minyak jenis minyak biosolar yaitu kadar residu karbon dan kandungan sulfur. Setelah keseluruhan data yang dibutuhkan tersedia, selanjutnya peneliti melakukan pengolahan data dengan menggunakan Six Sigma. Berikut ini tahapan pengolahan data:

1. Tahapan Define

Pada tahapan ini akan dilakukan identifikasi terhadap Critical to Quality dari produk bahan bakar minyak jenis minyak biosolar, yang terdiri dari kadar residu Karbon dan kandungan sulfur. 
2. Tahapan Measure

Pada tahapan ini akan dilakukan analisa terhadap data hasil pengukuran dengan menggunakan konsep six sigma untuk mengetahui kapabilitas proses, peta kendali, nilai defect per opportunity, defect per million opportunity dan level sigma terhadap critical to quality. Setelah mendapatkan nilai DPMO, maka dilakukan perhitungan level sigma. Jika level sigma yang didapatkan tidak ada dalam tabel sigma, maka dilakukan interpolasi level sigma dengan menggunakan persamaan interpolasi.

3. Tahapan Analyze

Tujuan dari tahapan ini adalah melakukan identifikasi dan analisa lebih lanjut terhadap faktor-faktor yang mempengaruhi kualitas biosolar dengan memperhatikan hasil pengolahan data pada tahapan measure berdasarkan peta kendali, kapabilitas proses dan level sigma dari setiap critical to quality. Hasil analisa pada tahapan ini akan digambarkan lewat fishbone diagram.

4. Tahapan Improve

Tahap ini akan diuraikan tentang rencana perbaikan untuk meningkatkan kualitas produk.

\section{HASIL DAN PEMBAHASAN}

\section{Tahap Define}

Seperti yang telah dijelaskan sebelumnya, kadar residu karbon yang tinggi akan menyebabkan menumpuknya residu karbon dalam ruang pembakaran, sehingga mengurangi kinerja mesin. Kadar karbon yang diijinkan untuk bahan bakar motor Diesel berkisar antara 0,15 - 0,35 \% wt (ASTM: 1991). Selain itu, kandungan Sulfur pada bahan bakar solar akan menyebabkan terjadinya keausan pada bagian mesin yang dikarenakan keberadaan oksida belerang yang terkandung di dalamnya (Rosyadi, 2016). Dua material ini sangat mempengaruhi kinerja mesin yang menggunakan produk biosolar. Untuk itu, PT Pertamina (Persero) menetapkan standar ketat untuk keduanya, sebagaimana ditunjukkan pada Tabel berikut:

Standar Kualitas Produk Biosolar

\begin{tabular}{|c|c|}
\hline Karakteristik Spesifikasi & Standar \\
\hline Kadar residu karbon & Max $1,0 \mathrm{~m} / \mathrm{m}$ \\
\hline Kandungan Sulfur & Max $0,25 \% \mathrm{~m} / \mathrm{m}$ \\
\hline
\end{tabular}

PT Pertamina menargetkan kandungan Sulfur turun menjadi 0,05\% m/m pada 1 Januari 2021, dan akan menjadi $0,005 \% \mathrm{~m} / \mathrm{m}$ pada 1 Januari 2025.

\section{Tahap Measure}

Pada tahap ini, pertama-tama dilakukan pengukuran kadar residu karbon dan kandungan sulfur dari sampel yang diambil. Sampel diambil sebanyak $100 \mathrm{ml}$, dari tangki penampungan produk biosolar sebanyak $10.000 \mathrm{kl}$. Hasil pengukuran kadar residu karbon dan kandungan sulfur ditunjukkan pada Tabel berikut secara berurutan. Selanjutnya, dilakukan penggambaran peta kendali dan kapabilitas proses, masing-masing untuk kadar residu karbon dan kandungan sulfur.

Hasil Pengukuran Kadar Residu Karbon

\begin{tabular}{|c|c|c|c|c|c|c|}
\hline \multirow{2}{*}{ Sampel } & \multicolumn{7}{|c|}{ Hasil Pengukuran $(\% \mathrm{~m} / \mathrm{m})$} \\
\cline { 2 - 7 } & Januari & Februari & Maret & April & Mei & Juni \\
\hline 1 & 0,6 & 0,6 & 0,5 & 0,8 & 0,8 & 0,7 \\
\hline 2 & 0,5 & 0,7 & 0,9 & 0,5 & 0,7 & 0,6 \\
\hline 3 & 0,8 & 0,9 & 0,8 & 0,7 & 0,6 & 0,8 \\
\hline 4 & 0,6 & 0,5 & 0,8 & 0,8 & 0,5 & 0,7 \\
\hline 5 & 0,6 & 0,6 & 0,7 & 0,6 & 0,7 & 0,8 \\
\hline 6 & 0,7 & 0,7 & 0,7 & 0,8 & 0,7 & 0,5 \\
\hline 7 & 0,5 & 0,6 & 0,9 & 0,7 & 0,8 & 0,8 \\
\hline 8 & 0,6 & 0,6 & 0,8 & 0,7 & 0,5 & 0,6 \\
\hline 9 & 0,5 & 0,8 & 0,9 & 0,6 & 0,7 & 0,8 \\
\hline 10 & 0,5 & 0,9 & 0,7 & 0,8 & 0,6 & 0,6 \\
\hline 11 & 0,7 & 0,6 & 0,6 & 0,5 & 0,9 & 0,7 \\
\hline 12 & 0,6 & 0,5 & 0,8 & 0,7 & 0,6 & 0,6 \\
\hline 13 & 0,7 & 0,6 & 0,6 & 0,7 & 0,6 & 0,7 \\
\hline 14 & 0,8 & 0,7 & 0,5 & 0,6 & 0,8 & 0,9 \\
\hline 15 & 0,7 & 0,8 & 0,9 & 0,8 & 0,6 & 0,6 \\
\hline 16 & 0,5 & 0,6 & 1,0 & 0,6 & 0,5 & 0,7 \\
\hline 17 & 0,6 & 0,6 & 0,7 & 0,8 & 0,7 & 0,6 \\
\hline
\end{tabular}




\begin{tabular}{|c|c|c|c|c|c|c|}
\hline \multirow{2}{*}{ Sampel } & \multicolumn{7}{|c|}{ Hasil Pengukuran (\% m/m) } \\
\cline { 2 - 7 } & Januari & Februari & Maret & April & Mei & Juni \\
\hline 18 & 0,8 & 0,7 & 0,6 & 0,5 & 0,8 & 0,8 \\
\hline 19 & 0,8 & 0,5 & 0,9 & 0,7 & 0,6 & 0,7 \\
\hline 20 & 0,7 & 0,9 & 0,5 & 0,6 & 0,7 & 0,7 \\
\hline 21 & 0,7 & 0,6 & 0,8 & 0,8 & 0,8 & 0,6 \\
\hline 22 & 0,8 & 0,6 & 0,8 & 0,7 & 0,6 & 0,8 \\
\hline 23 & 0,6 & 0,7 & 0,7 & 0,6 & 0,7 & 0,5 \\
\hline 24 & 0,9 & 0,5 & 0,9 & 0,7 & 0,7 & 0,8 \\
\hline 25 & 0,7 & 0,5 & 0,6 & 0,5 & 0,8 & 0,9 \\
\hline 26 & 1,0 & 0,8 & 0,8 & 0,7 & 0,6 & 0,9 \\
\hline 27 & 0,6 & 0,7 & 0,7 & 0,8 & 0,5 & 0,7 \\
\hline 28 & 0,5 & 0,7 & 0,8 & 0,7 & 0,6 & 0,8 \\
\hline 29 & 0,5 & 0,9 & 0,8 & 0,7 & 0,7 & 0,7 \\
\hline 30 & 0,8 & 0,6 & 0,6 & 0,6 & 0,7 & 0,6 \\
\hline
\end{tabular}

Hasil Pengukuran Kandungan Sulfur

\begin{tabular}{|c|c|c|c|c|c|c|}
\hline \multirow{2}{*}{ Sampel } & \multicolumn{7}{|c|}{ Hasil Pengukuran $(\% \mathrm{~m} / \mathrm{m})$} \\
\cline { 2 - 7 } & Januari & Februari & Maret & April & Mei & Juni \\
\hline 1 & 0,10 & 0,15 & 0,12 & 0,15 & 0,12 & 0,10 \\
\hline 2 & 0,08 & 0,10 & 0,12 & 0,12 & 0,09 & 0,15 \\
\hline 3 & 0,09 & 0,20 & 0,15 & 0,10 & 0,10 & 0,20 \\
\hline 4 & 0,15 & 0,10 & 0,08 & 0,12 & 0,12 & 0,15 \\
\hline 5 & 0,08 & 0,15 & 0,18 & 0,09 & 0,20 & 0,12 \\
\hline 6 & 0,08 & 0,09 & 0,15 & 0,10 & 0,16 & 0,12 \\
\hline 7 & 0,12 & 0,12 & 0,10 & 0,12 & 0,21 & 0,09 \\
\hline 8 & 0,12 & 0,15 & 0,20 & 0,15 & 0,10 & 0,06 \\
\hline 9 & 0,15 & 0,10 & 0,15 & 0,10 & 0,10 & 0,10 \\
\hline 10 & 0,08 & 0,11 & 0,12 & 0,09 & 0,12 & 0,15 \\
\hline 11 & 0,18 & 0,07 & 0,09 & 0,10 & 0,15 & 0,20 \\
\hline 12 & 0,15 & 0,15 & 0,06 & 0,15 & 0,08 & 0,12 \\
\hline 13 & 0,10 & 0,12 & 0,10 & 0,16 & 0,18 & 0,10 \\
\hline 14 & 0,20 & 0,20 & 0,15 & 0,25 & 0,15 & 0,21 \\
\hline 15 & 0,15 & 0,20 & 0,20 & 0,15 & 0,10 & 0,20 \\
\hline 16 & 0,12 & 0,15 & 0,12 & 0,12 & 0,22 & 0,15 \\
\hline 17 & 0,09 & 0,10 & 0,10 & 0,12 & 0,15 & 0,12 \\
\hline 18 & 0,06 & 0,09 & 0,21 & 0,15 & 0,12 & 0,10 \\
\hline 19 & 0,10 & 0,20 & 0,20 & 0,10 & 0,09 & 0,15 \\
\hline 20 & 0,15 & 0,10 & 0,15 & 0,15 & 0,06 & 0,20 \\
\hline 21 & 0,20 & 0,12 & 0,12 & 0,20 & 0,10 & 0,15 \\
\hline 22 & 0,12 & 0,10 & 0,10 & 0,21 & 0,09 & 0,10 \\
\hline 23 & 0,21 & 0,25 & 0,15 & 0,12 & 0,20 & 0,11 \\
\hline 24 & 0,20 & 0,20 & 0,20 & 0,09 & 0,10 & 0,07 \\
\hline 25 & 0,08 & 0,15 & 0,15 & 0,10 & 0,12 & 0,15 \\
\hline 26 & 0,10 & 0,12 & 0,10 & 0,06 & 0,10 & 0,12 \\
\hline 27 & 0,12 & 0,10 & 0,11 & 0,10 & 0,21 & 0,15 \\
\hline 28 & 0,15 & 0,15 & 0,07 & 0,10 & 0,22 & 0,12 \\
\hline 29 & 0,20 & 0,20 & 0,15 & 0,12 & 0,15 & 0,10 \\
\hline 30 & 0,15 & 0,15 & 0,12 & 0,15 & 0,12 & 0,12 \\
\hline
\end{tabular}




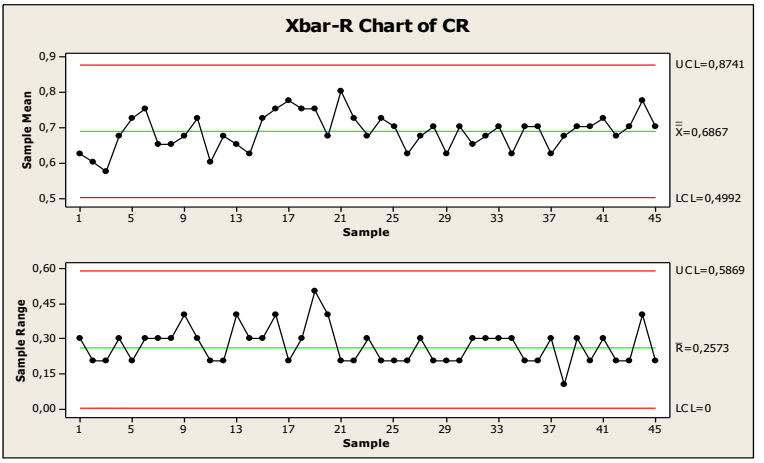

Peta Kendali $\bar{X}-\mathrm{R}$ Kadar Residu Karbon

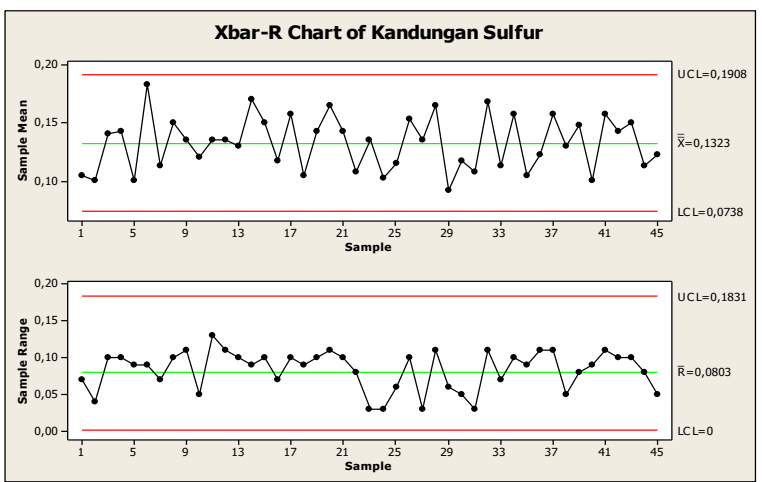

Peta Kendali X Bar R Kandungan Sulfur

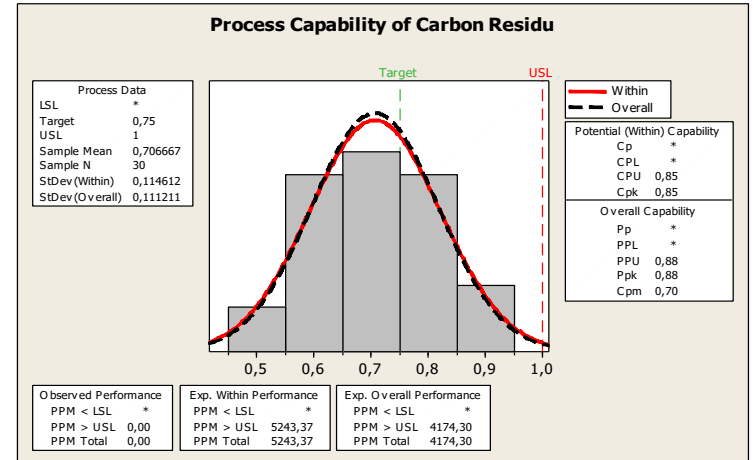

Kapabilitas Proses Kadar Residu Karbon

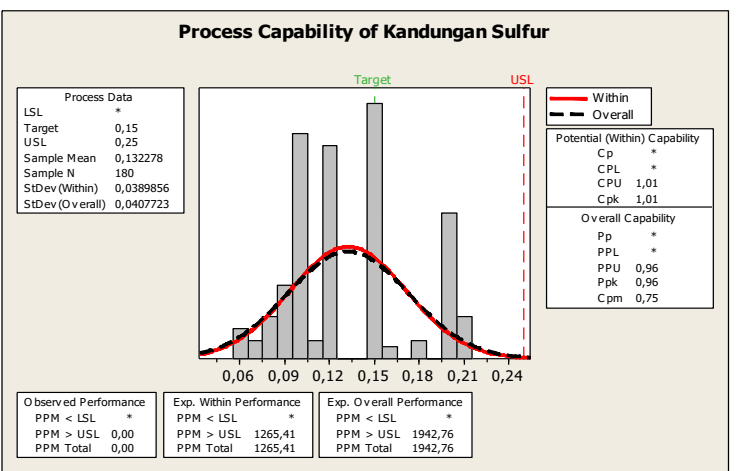

Kapabilitas Proses Kandungan Sulfur

Langkah selanjutnya pada tahap Measure adalah menghitung nilai Defect per Opportunity, Defect per Million Opportunity dan Nilai Sigma dari karakteristik kadar residu karbon dan kandungan sulfur, menggunakan Persamaan (1) - (3). Hasilnya dilihat pada Tabel berikut:

Hasil Perhitungan DPO, DPMO dan Nilai Sigma

\begin{tabular}{|l|c|c|c|}
\hline \multicolumn{1}{|c|}{ Karakteristik Kualitas } & DPO & DPMO & Level Sigma \\
\hline Kadar Residu Karbon & 0,002 & 19.000 & 3,575 \\
\hline Kandungan Sulfur & 0,0008 & 39.000 & 3,263 \\
\hline
\end{tabular}

\section{Tahap Analyze}

Peta kendali kadar residu Karbon menunjukkan nilai Upper Control Limit yaitu 0,8741\% m/m dan nilai Lower Control Limit yaitu $0,4992 \% \mathrm{~m} / \mathrm{m}$ dengan nilai rata-rata adalah $0,6876 \% \mathrm{~m} / \mathrm{m}$. Begitu juga nilai range memiliki Upper Control Limit yaitu 0,5869 dan nilai Lower Control Limit adalah 0 sedangkan nilai rata-rata range adalah 0,2573 . Dengan demikian, semua proses ada dalam batas kendali yang ditentukan oleh perusahaan. Kapabilitas proses kadar residu Karbon memiliki nilai $\mathrm{Cp}$ adalah 0,85 dan nilai Pp adalah 0,88, dan nilai $\mathrm{Cpm}$ adalah 0,70 yang menunjukkan bahwa proses produksi perlu dilakukan perbaikan sehingga hasil yang didapatkan juga memenuhi spesifikasi.

Peta kendali kandungan sulfur menunjukkan nilai Upper Control Limit yaitu 0,1908\% v/v dan nilai Lower Control Limit yaitu 0,0738\% v/v dengan nilai rata-rata adalah 0,1323\% v/v. Begitu juga nilai range memiliki Upper Control Limit yaitu 0,1831 dan nilai Lower Control Limit adalah 0 sedangkan nilai ratarata range adalah 0,0803 . Dengan demikian, semua proses ada dalam batas kendali yang ditentukan oleh perusahaan. Kapabilitas proses kandungan sulfur memiliki nilai $\mathrm{Cp}$ adalah 1,01, nilai Pp adalah 0,96 dan nilai $\mathrm{Cpm}$ adalah 0,75 yang menunjukkan bahwa proses produksi perlu dilakukan perbaikan sehingga hasil yang didapatkan juga memenuhi spesifikasi.

Perbandingan Level Kualitas Dengan Standar Kualitas Industri

\begin{tabular}{|c|c|c|c|c|c|c|}
\hline \multirow{2}{*}{ Karakteristik } & \multicolumn{2}{|c|}{ Perolehan Nilai } & \multicolumn{2}{c|}{$\begin{array}{c}\text { Standar Kualitas Industri } \\
\text { Global }\end{array}$} & \multicolumn{2}{c|}{$\begin{array}{c}\text { Standar Kualitas } \\
\text { Industri Indonesia }\end{array}$} \\
\cline { 2 - 7 } & DPMO & $\begin{array}{c}\text { Level } \\
\text { Kualitas }\end{array}$ & DPMO & $\begin{array}{c}\text { Level } \\
\text { Kualitas }\end{array}$ & DPMO & $\begin{array}{c}\text { Level } \\
\text { Kualitas }\end{array}$ \\
\hline Kadar residu karbon & 19.000 & 3,575 & \multirow{2}{*}{3,4} & 6 & 66.807 & 3 \\
\hline Kandungan sulfur & 39.000 & 3,263 & 6 & & 3 \\
\hline
\end{tabular}


Tabel di atas menguraikan perbandingan perolehan level kualitas biosolar di PT Pertamina (Terminal) BBM Wayame dengan standar kualitas industri kelas dunia dan industri di Indonesia yang menunjukkan bahwa perhitungan dengan menggunakan konsep six sigma memperoleh nilai keseluruhan DPMO karakteristik spesifikasi biosolar kurang dari standar kualitas industri kelas dunia namun lebih dari nilai standar kualitas perolehan DPMO di Indonesia. Perhitungan keseluruhan level kualitas memperoleh nilai kualitas biosolar yang kurang dari standar kualitas industri kelas dunia namun lebih dari nilai standar level kualitas industri di Indonesia. Oleh karena itu, dengan adanya penerapan six sigma, perusahaan dapat melakukan pengendalian kualitas secara ketat untuk mendapatkan level kualitas produk berdasarkan tujuan utama perusahaan. Untuk meningkatkan level kualitas biosolar sesuai dengan tujuan utama dari PT Pertamina (Persero) yaitu menjadi perusahaan energi kelas dunia, maka harus dilakukan solusi perbaikan untuk peningkatan kualitas sesuai dengan yang telah diuraikan pada tabel solusi peningkatan kualitas.

Tahap Improve

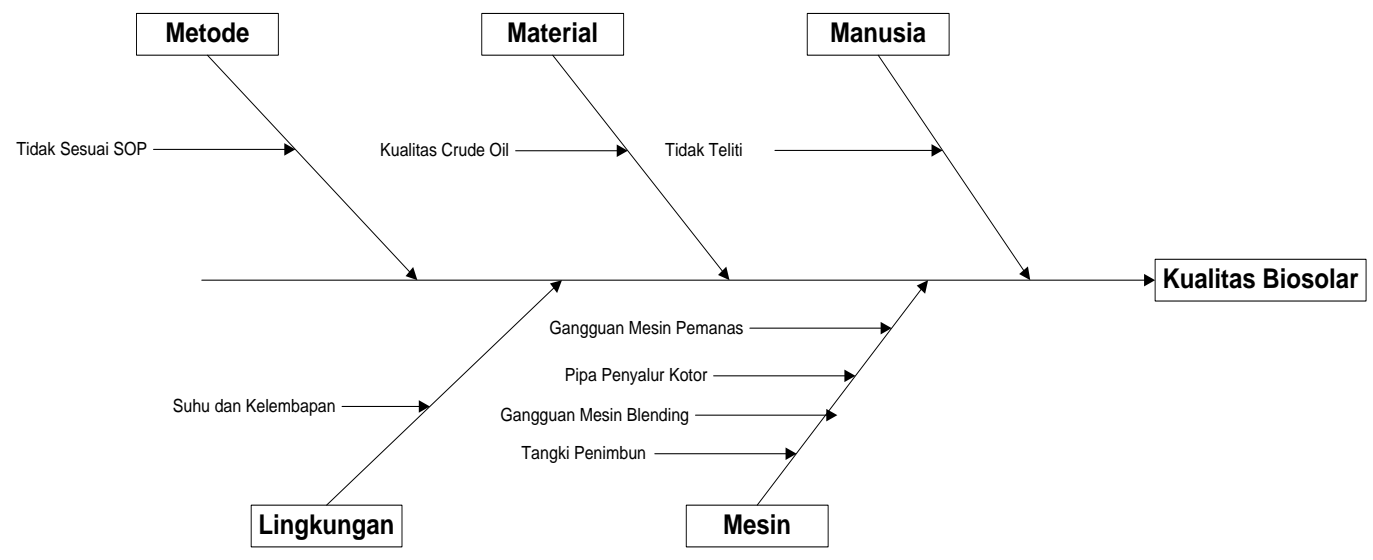

Fisbhone Diagram Kualitas Biosolar

Berdasarkan fishbone diagram di atas, maka terdapat beberapa usulan solusi perbaikan yang dapat dilakukan oleh PT Pertamina (Persero) Terminal BBM Wayame, untuk membantu meningkatkan kualitas produksi minyak biosolar yang dihasilkan. Solusi dibagi berdasarkan faktor penyebab menurunya kualitas produk yang dihasilkan. Secara terperinci, solusi perbaikan diuraikan pada Tabel berikut:

Solusi Peningkatan Kualitas

\begin{tabular}{|c|c|c|}
\hline No & $\begin{array}{l}\text { Faktor-Faktor } \\
\text { Penyebab }\end{array}$ & Solusi Perbaikan \\
\hline 1 & Manusia & $\begin{array}{l}\text { A. Meningkatkan kemampuan Sumber Daya Manusia (SDM) pekerja dengan } \\
\text { melakukan pelatihan terkait dengan Standar Operasional Prosedur (SOP) } \\
\text { proses blending bahan bakar minyak jenis minyak biosolar. } \\
\text { B. Mengatur waktu kerja atau waktu operasional dari masing-masing pekerja, } \\
\text { seperti menerapkan sistem kerja bergilir. }\end{array}$ \\
\hline 2 & Mesin & $\begin{array}{l}\text { A. Perlu di lakukannya pemeriksaan dan perawatan secara rutin terhadap mesin- } \\
\text { mesin yang beroperasi pada saat proses produksi. } \\
\text { B. Pembersihan terhadap pipa penyalur dan tangki penimbun dari kotoran } \\
\text { seperti lumut. }\end{array}$ \\
\hline 3 & Metode & $\begin{array}{l}\text { A. Pengawasan yang ketat terhadap Standar Operasional Prosedur (SOP) yang } \\
\text { telah ditetapkan. }\end{array}$ \\
\hline 4 & Material & $\begin{array}{l}\text { A. Meningkatakan kualiats crude oil atau minyak mentah dengan melakukan } \\
\text { proses pengendalian yang ketat seperti melakukan proses pemeriksaan setiap } \\
\text { parameter kualitas bahan bakar minyak sebelum proses produksi. }\end{array}$ \\
\hline 5 & Lingkungan & $\begin{array}{l}\text { A. Melakukan pembersihan terhadap daerah selokan di sekitar tangki penimbun } \\
\text { yang tersumbat, karena dapat menyebabkan kelembapan pada bagian bawah } \\
\text { tangki. }\end{array}$ \\
\hline
\end{tabular}

\section{KESIMPULAN}

Tingkat pencapaian kualitas dengan konsep six sigma untuk level kualitas rata-rata industri kelas dunia yang memenuhi standar adalah 6,00. Perolehan level kualitas karakteristik spesifikasi biosolar adalah sebagai berikut: 
a) Kadar residu Karbon memiliki level kualitas 3,575

b) Kandungan Sulfur memiliki level kualitas 3,263

Hasil perolehan keseluruhan level kualitas spesifikasi biosolar di PT Pertamina (Persero) Terminal BBM Wayame, menunjukkan bahwa karakteristik spesifikasi biosolar masih berada dibawah rata-rata level kualitas industri kelas dunia, namun telah memenuhi pencapaian level kualitas yang berlaku di Indonesia yaitu 3,00 .

\section{DAFTAR PUSTAKA}

Assauri, S. (2011). Manajemen Pemasaran Dasar Konsep dan Strategi. PT RajaGrafindo Persada, Jakarta, 09(2), 168-169. https://doi.org/10.1109/ACC.2007.4282338

Bentley, W., \& Davis, P. (2009). Lean and Six Sigma Resources. Lean Six Sigma Secrets for the CIO, 269270. https://doi.org/10.1201/9781439803820.axf

Fauziah, A., Harsono, A., \& Liansari, G. P. (2014). Usulan Perbaikan Kualitas Menggunakan Metode Six Sigma Untuk Mengurangi Jumlah Cacat Produk Tahu Pada Perusahaan Pengrajin Tahu Boga Rasa. Jurnal Online Institut Teknologi Nasional, 02(04), 166-176.

Feigenbaum, A. V. (2019). DR. ARMAND V. FEIGENBAUM. The Feigenbaum Foundation.

Gaspersz, V. (1998). Manajemen Produktivitas Total Strategi Oeningkatan Produktivitas Bisnis Global. Gramedia Pustaka Utama, Jakarta, 1-311.

George, M. L. (2003). Lean Six Sigma for Service: How to Use Lean Speed and Six Sigma Quality to Improve Services and Transactions. In Group. https://doi.org/10.1036/0071436359

Juran, J. M. (1999). the Quality Improvement Process the Remainder of This Section 5 . 7 Quality Improvement : the Basic. The Quality Improvement Process, $1-73$.

Rosyadi, I, Setiawan, I, Haryadi, Suhendri. (2016). Kajian tentang Penggunaan Bahan Bakar Biosolar Murni dan Campurannya Menggunakan Minyak Jarak pada Mesin Disel Satu Silinder. FLYWHEEL: Jurnal Teknik Mesin Untirta, 2(02), 64-72

Yang, K., \& El-haik, B. (2003). Design for Six Sigma A Roadmap for Product Development. In McGraw Hill Professional. https://doi.org/10.1036/0071435999 